\title{
Tracheal epithelial damage alters the effects of luminal histamine on blood flow and tracer flux in anaesthetized sheep
}

\author{
U.M. Wells, Z. Hanafi, J.G. Widdicombe
}

Tracheal epithelial damage alters the effects of luminal histamine on blood flow and tracer flux in anaesthetized sheep. U.M. Wells, Z. Hanafi, J.G. Widdicombe. (CERS Journals Ltd 1996.

ABSTRACT: Epithelial damage greatly increases the flux of a low molecular weight tracer ${ }^{99}$ technetium-diethylenetriamine penta-acetic acid $\left({ }^{99 m}\right.$ Tc-DTPA) from tracheal lumen to venous-blood in anaesthetized sheep. We have now investigated whether epithelial damage induced by the detergent, Triton X-100, alters the effects of luminal histamine on blood flow and 99mTc-DTPA flux.

The cervical trachea was filled with Krebs-Henseleit solution containing ${ }^{99 m}$ TcDTPA. Tracheal arterial flow was measured and tracheal venous blood collected. The lumen was exposed to $100 \mu \mathrm{M}$ histamine on two occasions (Hist 1 and Hist 2) for $15 \mathrm{~min}$. In six out of 11 sheep, the lumen was also exposed to $0.2 \%$ Triton $X$ 100 between Hist 1 and Hist 2.

Triton X-100 increased the baseline ${ }^{99 \mathrm{~m}}$ Tc-DTPA permeability coefficient from $-5.3 \times 10^{-7}$ to $-400 \pm 130 \times 10^{-7} \mathrm{~cm} \cdot \mathrm{s}^{-1}$. After epithelial damage, Hist 2 produced significantly greater changes in arterial and venous flows than Hist $1(n=5)(0-5$ min: Hist $1 Q^{\prime}{ }^{\prime}=+6.4 \pm 0.8 \%, Q^{\prime}=+6.2 \pm 6.2 \%$; Hist $\left.2 Q^{\prime} \mathrm{a}=+36.7 \pm 12.2 \%, Q^{\prime} \mathrm{v}=+35.4 \pm 8.8 \%\right)$. Similar changes did not occur in the controls. Venous ${ }^{99 m}$ Tc-DTPA concentration during Hist 2 after epithelial damage $(0-5 \mathrm{~min}-37.7 \pm 6.9 \%)$ was significantly different from Hist $1(+5.2 \pm 7.0 \%)$.

Thus, after epithelial damage, luminal histamine produces more rapid and larger changes in blood flow and a greater reduction in venous ${ }^{99 m}$ Tc-DTPA concentration.

Eur Respir J., 1996, 9, 78-85.
Dept of Physiology, St George's Hospital Medical School, London, UK

Correspondence: U. Wells

Dept of Physiology

St George's Hospital Medical School London SW17 0RE

UK

Keywords: Airway permeability

histamine

mucosal blood flow

tracheal epithelium

Received: January 41995

Accepted after revision August 181995
It has been established by in vitro studies [1-3] that the airway epithelium is a barrier to the movement of low molecular weight hydrophilic compounds. However, recent studies in vivo measuring the movement of $99 \mathrm{~m}$ technetium-diethylenetriamine penta-acetic acid (99mTc-DTPA, a low molecular weight hydrophilic tracer of similar size to many drugs given by inhalation) from the tracheal lumen to venous blood suggest that the relevance of in vitro studies on permeability may be limited, for two reasons.

Firstly, damage to the sheep tracheal epithelium in vivo increased the permeability coefficient of $99 \mathrm{mTc}-$ DTPA (PDTPA) by a factor of 120 [4], a much greater change than that found in vitro using this tracer or other solutes of similar molecular weight [1-3]. This may be because the presence of a functional subepithelial capillary bed results in the sweeping away of the tracer in the bloodstream, thus altering both the flux and the concentration gradient of the tracer between tracheal lumen and the mucosa. Secondly, PDTPA is also greatly affected by changes in blood flow [5]. A negative relationship exists between venous ${ }^{99}$ Tc-DTPA uptake and blood flow. The reason is unknown but may be related to changes in capillary fluid flux.

Bronchoconstrictor agents, such as methacholine and histamine, cause vasodilatation, and when injected into the tracheal circulation markedly decrease PDTPA [5]. These drugs are often given by inhalation in provocation testing; asthmatics show an increased sensitivity, as measured by lung function tests $[6,7]$. This may be due, at least in part, to an increase in drug penetration across the epithelium to the airway smooth muscle [8, 9]. Despite these observations, the effects of intraluminal administration of these drugs on blood flow and airway permeability of low molecular weight solutes and whether these effects are enhanced by epithelial damage has not been investigated in vivo.

We have therefore measured the effect of luminal histamine on tracheal arterial and venous flows and PDTPA before and after inducing epithelial damage by exposure of the sheep tracheal lumen to a detergent, Triton X100 . 


\section{Materials and methods}

Fourteen sheep (female, 25-30 kg) were used, three in a study to test whether $100 \mu \mathrm{M}$ histamine had a submaximal effect on tracheal blood flow, and 11 in a study on the effect of epithelial damage on responses to histamine.

\section{Experimental preparation}

Experimental preparation has been described previously $[5,10]$. Female sheep $(25-30 \mathrm{~kg})$ were anaesthetized with sodium pentobarbitone (initially $20 \mathrm{mg} \cdot \mathrm{kg}^{-1}$ i.v.) and additional doses were given to maintain surgical anaesthesia. The animals were in the supine position. The right external jugular vein was catheterized ( 8 FG, Portex). All animals were paralysed with an intravenous injection of gallamine triethiodide $\left(1 \mathrm{mg} \cdot \mathrm{kg}^{-1}\right.$ initially), and ventilated via a tracheal cannula inserted in the lower cervical trachea. The tidal volume was 12-16 $\mathrm{mL} \cdot \mathrm{kg}^{-1}$ and the frequency 28 breaths $\cdot \mathrm{min}^{-1}$. The right femoral artery was catheterized (8 FG, Portex) and the catheter was connected to a pressure transducer (P231D; Gould) for measurement of systemic arterial blood pressure.

A tracheal artery branching from the left carotid artery was isolated, and the left carotid artery was ligated cranial to this, so that blood would only perfuse the trachea (fig. 1). Branches perfusing other tissues were tied off. The occluded segment of the left carotid artery was bypassed from the right carotid artery using a plastic Ytube connection.

An electromagnetic flow-probe was inserted between two catheters into the left carotid artery supplying the isolated region of perfusion. The flow-probe was connected to a square-wave electromagnetic flowmeter (Carolina Medical Electronics) and tracheal arterial flow was recorded continuously throughout the experiment. The mean flow for each 5 min period of the experiment was calculated, using measurements taken at 1 min intervals.

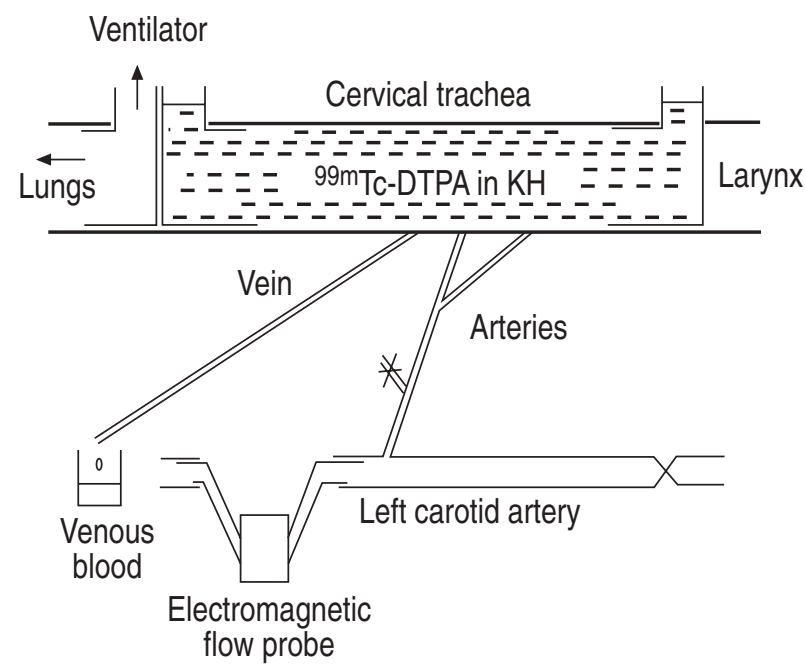

Fig. 1. - Experimental set-up. 99mTc-DTPA: 99mtechnetium-diethylenetriamine penta-acetic acid; KH: Krebs-Henseleit solution.
A vein on the left side and draining the perfused region of the trachea was isolated and catheterized (3 FG, Portex). Venous blood was collected for 5 min periods continuously throughout the experiment. The distribution of perfused tracheal circulation was tested by close-arterial injection of Evans blue dye diluted in $0.15 \mathrm{M} \mathrm{NaCl}$.

The cervical trachea was isolated by inserting two balloon-cuffed tracheostomy tubes into the trachea, one below the larynx and the other just above the low cervical tracheostomy supplying airflow to the lungs. The enclosed segment was usually $10-15 \mathrm{~cm}$ long and included the area perfused by the isolated tracheal artery.

\section{Protocols}

Throughout the experiment the tracheal lumen was filled with a known volume of Krebs-Henseleit solution (KH) for $15 \mathrm{~min}$ periods. The $\mathrm{KH}$ contained $99 \mathrm{~m} \mathrm{Tc}-$ DTPA unless otherwise stated. At the end of each period the KH was withdrawn and replaced. Two sets of experiments were performed and in each the lumen was exposed to histamine (in $\mathrm{KH}$ ) for 15 min periods. Experiments lasted for $3.25 \mathrm{~h}$.

\section{Histamine concentration-response study}

To test whether $100 \mu \mathrm{M}$ luminal histamine produced a submaximal effect on arterial flow, three experiments were carried out, in each of which three concentrations of histamine $(10 \mu \mathrm{M}, 100 \mu \mathrm{M}$ and $1 \mathrm{mM})$ were given in a random order. The first concentration was washed into the lumen $45 \mathrm{~min}$ after the start of the experiment, and there were three control periods between each administration. In these experiments, the $\mathrm{KH}$ did not contain 99mTc-DTPA and venous blood was not collected.

\section{Effect of epithelial damage on response to luminal his- tamine}

In 11 sheep, histamine $(100 \mu \mathrm{M})$ was washed into the tracheal lumen during the fourth (Hist 1) and eleventh (Hist 2) periods. In six of these experiments, epithelial damage was induced during the seventh period by washing $0.2 \%$ Triton $\mathrm{X}-100$ in $\mathrm{KH}$ into the lumen. For technical reasons, arterial flow was not measured in one experiment and venous flow (and hence 99mTc-DTPA concentration and output) in one other experiment.

In the five control experiments, epithelial damage was not induced. Venous flow was not measured in one experiment. $99 \mathrm{mTc}-\mathrm{DTPA}$ concentration and output were not measured in the control experiments.

\section{Measurement of venous ${ }^{99 m}$ Tc-DTPA concentration and output}

Venous flow per 5 min was determined by weighing the venous blood samples. The $99 \mathrm{mTc}-\mathrm{DTPA}$ concentration (counts. $\mathrm{min}^{-1} \cdot \mathrm{mL}^{-1}$ ) in each sample was measured 
using a gamma counter (Beckman Gamma 5500). The 99mTc-DTPA concentration was multiplied by venous flow to obtain the total $99 \mathrm{mTc}$-DTPA output (counts. $\mathrm{min}^{-2}$ ) in the catheterized vein for each $5 \mathrm{~min}$ period. Thus, three measurements of venous 99mTc-DTPA output were obtained during each 15 min exposure to KH. The background level of 99mTc-DTPA in systemic blood was measured in femoral arterial samples taken at 15 or $30 \mathrm{~min}$ intervals throughout the experiment.

\section{Measurement of potential difference}

The electrical potential difference (PD) across the tracheal wall was measured using two calomel reference electrodes. These were filled with $3.8 \mathrm{M} \mathrm{KCl}$ and placed in separate beakers of the same solution. Electrical contact was made with the preparation using two agar bridges constructed from polyethylene tubing $(0.5 \mathrm{~mm}$ internal diameter) filled with $3.8 \mathrm{M} \mathrm{KCl}$ in $2.5 \%$ (w/v) agar solution. The end of one agar bridge was inserted into the lumen of the isolated segment of trachea via the lower cannula; the end of the other bridge was placed in a pool of saline touching the external tracheal wall. Output from the two electrodes was via a high input impedance buffer amplifier $\left(>10^{9} \mathrm{M} \Omega\right.$ ) and displayed on a digital voltmeter.

\section{Analysis of results}

The results for tracheal arterial flow, venous flow, 99mTc-DTPA concentration and $99 \mathrm{~m}$ Tc-DTPA output during each $5 \mathrm{~min}$ of the $15 \mathrm{~min}$ test and post-test periods were calculated as mean $( \pm$ SEM) percentage changes from the last $5 \mathrm{~min}$ of the pretest controls. The statistical significance of changes was tested using Student's two-tailed paired t-tests by comparison with the values of the last $5 \mathrm{~min}$ of the $15 \mathrm{~min}$ pretest controls.

The permeability coefficients for $99 \mathrm{mTc}$-DTPA were calculated during test periods and also during the control period immediately preceding the first test period in each experiment. The permeability coefficient, $\mathrm{P}=$ - $(\mathrm{d} Q / \mathrm{dt}) / \mathrm{S} \cdot \Delta \mathrm{C}$, where $\mathrm{d} Q / \mathrm{dt}$ is the output of $99 \mathrm{mTc}-$ DTPA in counts. $\mathrm{min}^{-2}$ and $\Delta \mathrm{C}$ is the concentration gradient of $99 \mathrm{~m}$ Tc-DTPA from tracheal lumen to venous blood in counts $\cdot \mathrm{min}^{-1} \cdot \mathrm{mL}^{-1}$ (i.e. the mean of the luminal concentration of 99mTc-DTPA at the start and end of the 15 min minus the mean 99mTc-DTPA concentration of the three 5 min venous samples). $\mathrm{S}$ is that part of the surface area of the isolated trachea that is perfused; we assume that it is constant throughout the experiment. Using Evans Blue injections, $\mathrm{S}$ was shown in an earlier study, using similar variety and weights of sheep, to be $30 \mathrm{~cm}^{2}$. This value, which is slightly smaller than the total surface area of the tracheal segment [5], has been used here. Because only part of the arterial blood is collected in the cannulated vein, it is also assumed that total 99mTc-DTPA uptake is the measured output multiplied by the ratio of arterial blood inflow to venous outflow [5]. The mean ( \pm SEM) permeability coefficients for each stimulus were compared using the Student's t-test.
Drugs

Evans blue dye was obtained from Aldrich Chemical Corp.; heparin sodium from CP Pharmaceuticals; gallamine triethiodide and sodium pentobarbitone (Sagatal) from May \& Baker; Triton X-100 from BDH; and histamine dihydrochloride from Sigma.

\section{Results}

\section{Luminal histamine concentration-response curve}

Histamine, $100 \mu \mathrm{M}$, produced a submaximal increase in arterial flow (fig. 2). A lower concentration (10 $\mu \mathrm{M})$ had no effect on arterial flow.

Effect of epithelial damage on responses to $100 \mu \mathrm{M}$ luminal histamine

Systemic arterial pressure. Systemic arterial pressure at the start of the experiments was $111 \pm 7 \mathrm{mmHg}(\mathrm{n}=5)$ in the control experiments and $111 \pm 8 \mathrm{mmHg}(\mathrm{n}=5)$ in the epithelial damage experiments. At the end of the experiment, these pressures were $94 \pm 3 \mathrm{mmHg}(\mathrm{n}=5)$ in the controls and $93 \pm 6 \mathrm{mmHg}(\mathrm{n}=5)$ in the epithelial damage experiments. These changes were statistically significant $(\mathrm{p}<0.05$, paired t-test). Systemic blood pressure was not significantly altered by Hist 1 or Hist 2 either in the control experiments or in the epithelial damage experiments.

Baseline tracheal arterial and venous flows. These are shown in table 1 . There were no significant differences in baseline flows between the control periods before each histamine administration, or between the epithelial damage and control experiments.

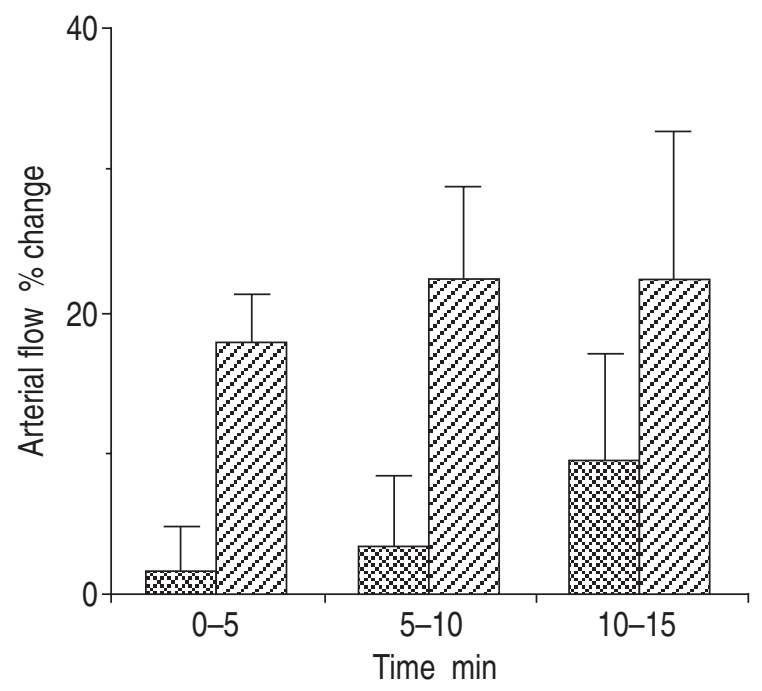

Fig. 2. - Mean percentage change in arterial flow during each 5 min of a $15 \mathrm{~min}$ exposure of tracheal lumen to $100 \mu \mathrm{M}$ or $1 \mathrm{mM}$ histamine $(n=3)$. Changes were normalized to the last $5 \mathrm{~min}$ of the preceding control periods. Vertical bars show SEM. $\square$ : $100 \mu \mathrm{M}$ histamine; $\square$ : $1 \mathrm{mM}$. 
Table 1. - Baseline tracheal blood flow in the 15 min before histamine (Hist) administration in epithelium (Ep) intact (control) and epithelial damage experiments

\begin{tabular}{|c|c|c|c|c|}
\hline & \multicolumn{2}{|c|}{ Before Hist 1} & \multicolumn{2}{|c|}{ Before Hist 2} \\
\hline & Ep intact & Ep damage & Ep intact & Ep damage \\
\hline Arterial flow $\mathrm{mL} \cdot \mathrm{min}^{-1}$ & $5.7 \pm 0.8$ & $6.0 \pm 1.0$ & $5.3 \pm 0.7$ & $5.0 \pm 0.5$ \\
\hline Venous flow $\mathrm{mL} \cdot \mathrm{min}^{-1}$ & $0.70 \pm 0.13$ & $0.79 \pm 0.09$ & $0.74 \pm 0.13$ & $0.71 \pm 0.07$ \\
\hline
\end{tabular}

Values are presented as mean \pm SEM. $n=5$, except venous flow in epithelium intact experiments $(n=4)$.

Arterial flow in response to histamine. Hist 1 produced a slow onset increase in arterial flow both in control (fig. 3) and experimental damage experiments (fig. 4a). There was no significant difference in arterial flow between Hist 1 and Hist 2 in the control experiments (fig. 3 ), but in tracheas exposed to Triton X-100, Hist 2 produced a more rapid and significantly larger increase in flow ( $<<0.05$, unpaired t-test) (fig. $4 \mathrm{~b})$. The maximum mean changes in arterial flow were $+49 \pm 9 \%$ after epithelial damage (during the middle $5 \mathrm{~min}$ of exposure to

a) Ep+/Hist 1

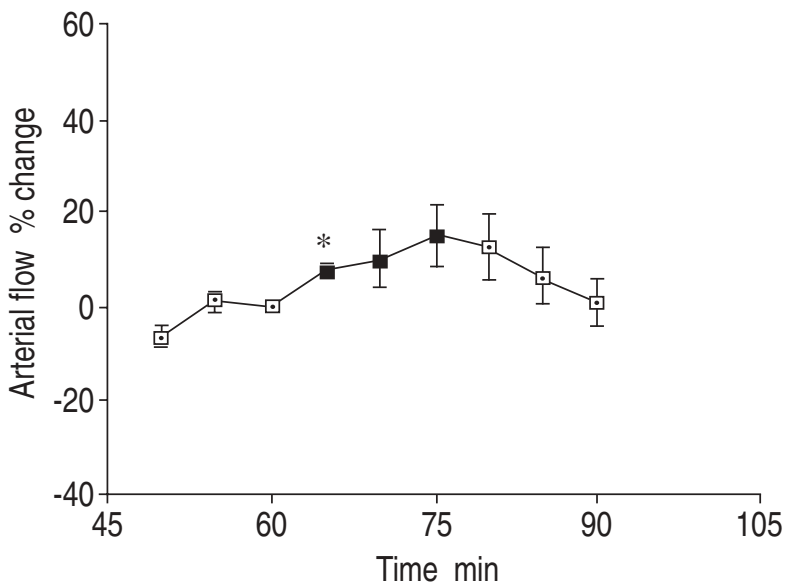

b) Ep+/Hist 2

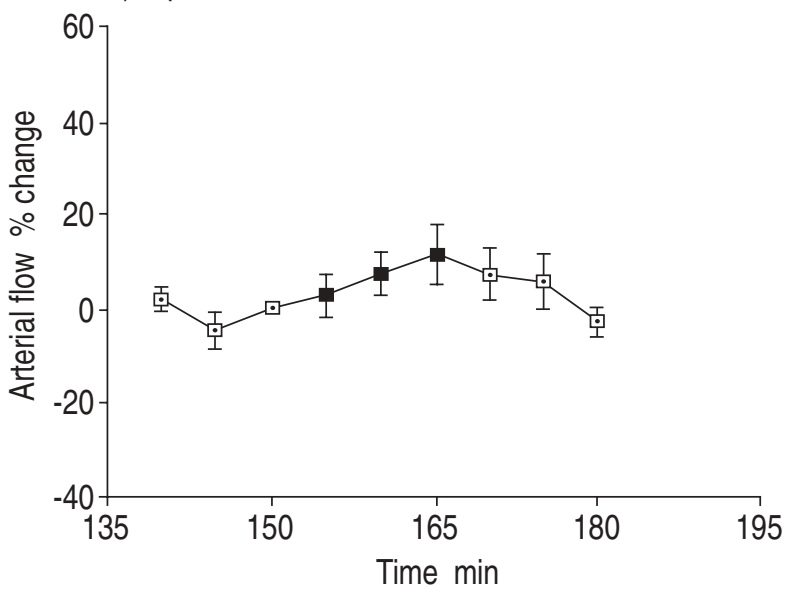

Fig. 3. - Intact epithelium controls. Tracheal arterial flow in response to exposure of the tracheal lumen with the epithelium (Ep) intact to two $15 \mathrm{~min}$ administrations of $100 \mu \mathrm{M}$ histamine (Hist) $(\mathrm{n}=5)$ : a) $\mathrm{Ep}+/$ Hist 1; and b) Ep+/Hist 2. Each point represents mean flow over a $5 \mathrm{~min}$ period. Results were normalized to the last $5 \mathrm{~min}$ of the preceding control. Filled squares represent period of exposure to histamine. Vertical bars show SEM. *: $\mathrm{p}<0.05$ ( $v$ s $10-15$ min preceding control, paired t-test).
Hist 2) compared with $+26 \pm 8 \%$ before epithelial damage (during the final $5 \mathrm{~min}$ of exposure to Hist 1$)(\mathrm{n}=5)$ (fig. 4). Arterial flow increased markedly within $10 \mathrm{~s}$ of adding the histamine to the trachea after epithelial damage. Time to half-maximal increase in flow was $1.6 \pm$ $0.3 \mathrm{~min}$, compared with $6 \pm 1 \mathrm{~min}$ in response to Hist 1 .

Venous flow in response to histamine. Similar changes in venous flow occurred (figs 5 and 6). In control experiments, both Hist 1 and Hist 2 produced a slow-onset

a) Ep+/Hist 1
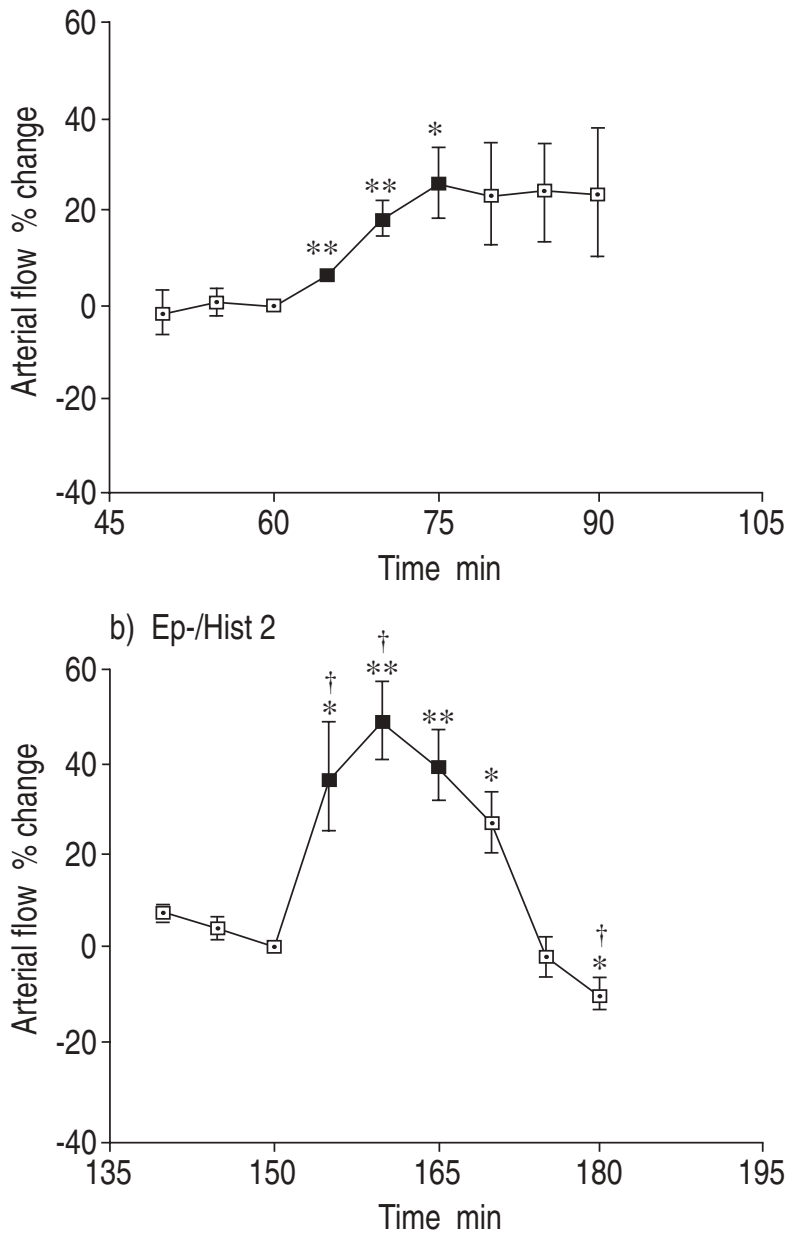

Fig. 4. - Epithelial damage. Tracheal arterial flow in response to two 15 min administrations of $100 \mu \mathrm{M}$ histamine (Hist) $(\mathrm{n}=5)$ : a) before (Ep+/Hist 1); and b) after epithelial damage induced by $0.2 \%$ Triton X-100 (Ep-/Hist 2). Each point represents mean flow over a 5 min period. Results were normalized to the last $5 \mathrm{~min}$ of the preceding control. Filled squares represent period of exposure to histamine. Vertical bars represent SEM. *: $\mathrm{p}<0.05$; **: $\mathrm{p}<0.01$ ( vs $10-15$ min preceding control, paired t-test); ${ }^{\dagger}: \mathrm{p}<0.05$ ( $v s$ Ep+/Hist 1, unpaired t-test). 
a) Ep+/Hist 1

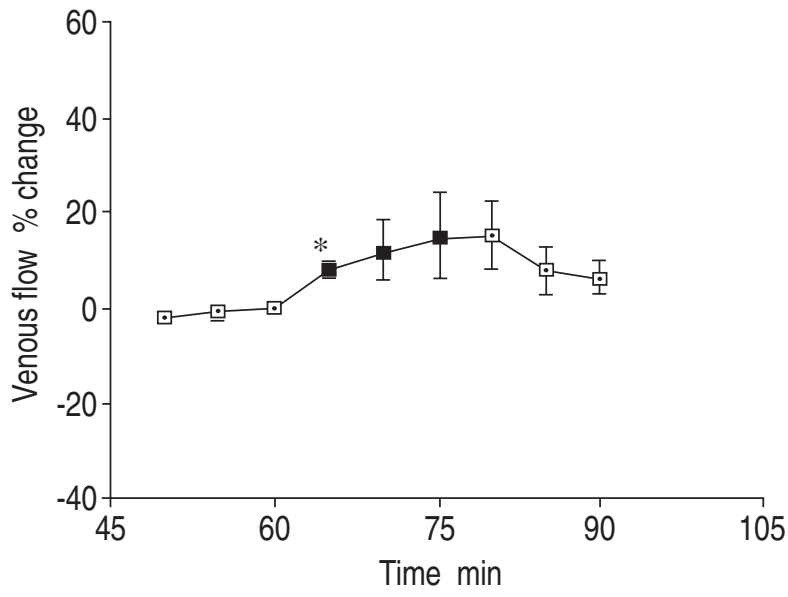

b) Ep+/Hist 2

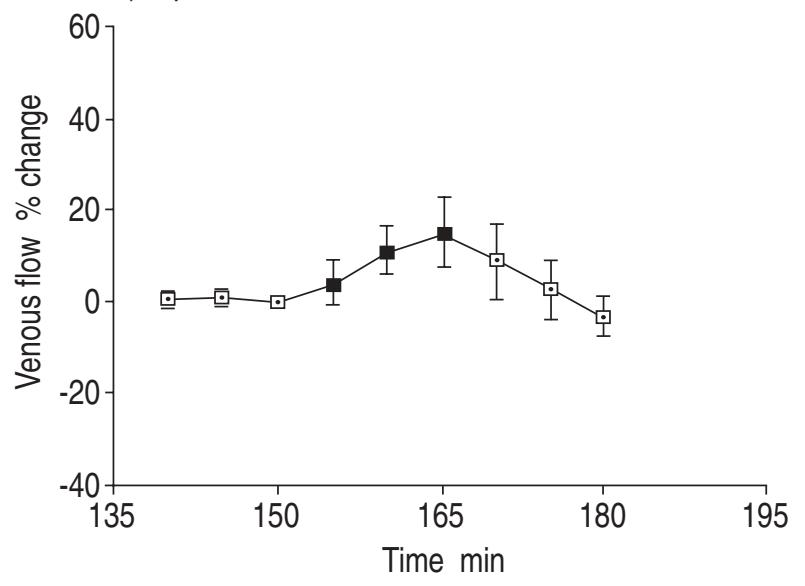

Fig. 5. - Intact epithelium control. Tracheal venous flow in response to exposure of the tracheal lumen with the epithelium (Ep) intact to two administrations of $100 \mu \mathrm{M}$ histamine (Hist) $(\mathrm{n}=4)$ : a) $(\mathrm{Ep}+/ \mathrm{Hist}$ 1; b) and Ep+/Hist 2. Each point represents mean flow over a $5 \mathrm{~min}$ period. Results were normalized to the last $5 \mathrm{~min}$ of the preceding control. Filled squares represent period of exposure to histamine. Vertical bars show SEM. *: $\mathrm{p}<0.05$ (vs 10-15 min preceding control, paired t-test).

increase in flow (fig. 5), whilst in tracheas with epithelial damage Hist 2 produced a more rapid increase in flow (fig. 6b). Mean venous flow during the first $5 \mathrm{~min}$ was significantly higher than in Hist $1(\mathrm{p}<0.05$, unpaired t-test). Venous flow returned to baseline during the first 5 min of the subsequent control period and was significantly below baseline for the final $5 \mathrm{~min}$.

Venous ${ }^{99 m}$ Tc-DTPA concentration and output. Venous 99mTc-DTPA concentration and output were measured only in the epithelial damage experiments. Both Hist 1 and Hist 2 decreased the concentration of $99 \mathrm{mTc}-\mathrm{DTPA}$ significantly (fig. 7). The mean changes were larger in Hist 2 following epithelial damage than in Hist 1; the effect was statistically significant during the first $5 \mathrm{~min}$ $(\mathrm{p}<0.01$, unpaired t-test) and just failed to reach significance during the second $5 \mathrm{~min}(\mathrm{p}=0.07)$. The effects both of Hist 1 and Hist 2 on venous 99mTc-DTPA concentration continued into the following control period. a) Ep+/Hist 1

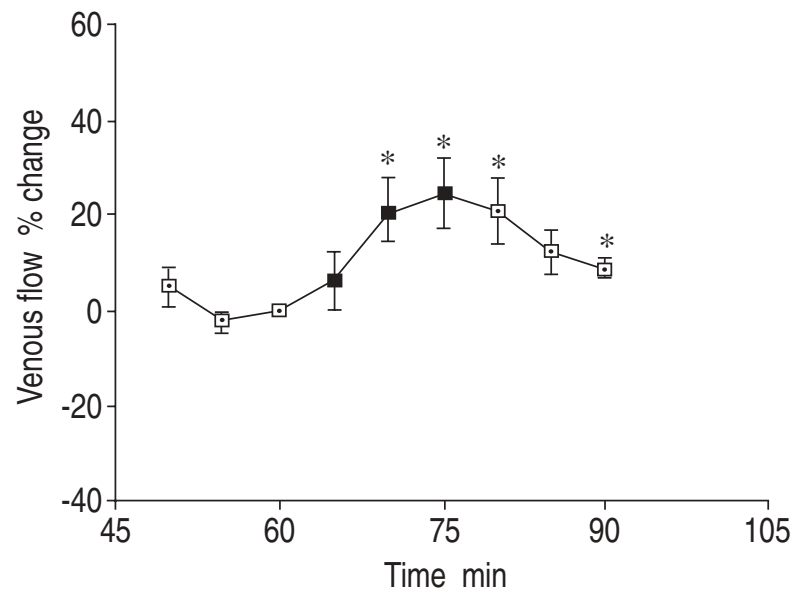

b) Ep-/Hist 2

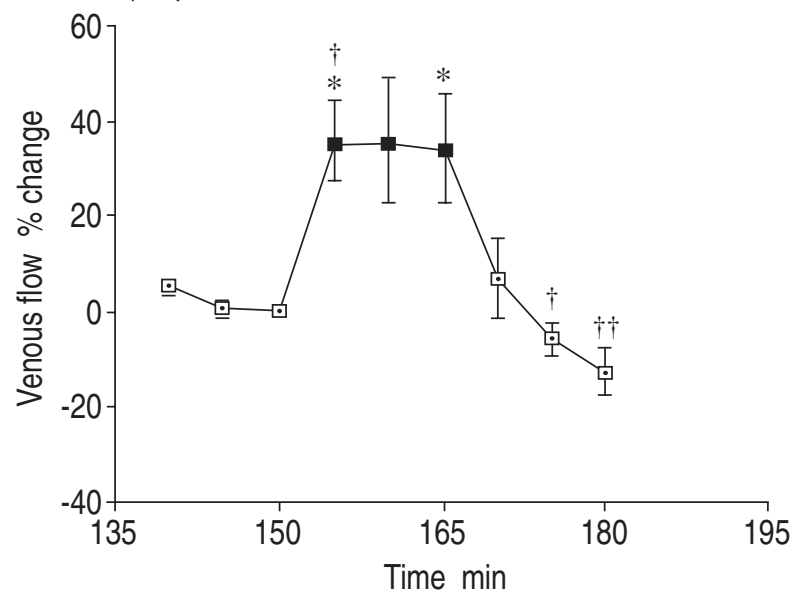

Fig. 6. - Epithelial damage. Tracheal venous flow in response to two 15 min administrations of $100 \mu \mathrm{M}$ histamine (Hist) $(n=5)$ : a) before (Ep+/Hist 1); and b) after epithelial damage induced by $0.2 \%$ Triton X-100 (Ep-/Hist 2). Each point represents mean flow over a 5 min period. Results were normalized to the last $5 \mathrm{~min}$ of the preceding control. Filled squares represent period of exposure to histamine. Vertical bars show SEM. *: $\mathrm{p}<0.05$ (vs 10-15 min preceding control, paired t-test); $\mathrm{p}<0.05$; $\uparrow \mathrm{p}<0.01$ ( $v s$ Ep+/Hist 1, unpaired t-test).

Hist 1 did not alter 99mTc-DTPA output significantly (fig. 8). However, after epithelial damage, ${ }^{99 \mathrm{mTc}-\mathrm{DTPA}}$ output was significantly decreased during Hist 2 and the following control period. The mean changes in $99 \mathrm{mTc}-$ DTPA output in Hist 2 were greater than those in Hist 1 , but the difference was significant only during the first 5 min of the exposure period $(\mathrm{p}<0.05$, unpaired t-test).

PDTPA. The baseline PDTPA could only be calculated in the four Triton X-100 experiments, in which both arterial and venous flows were measured. PDTPA was $-5.3 \pm 2.6 \times 10^{-7} \mathrm{~cm} \cdot \mathrm{s}^{-1}(\mathrm{n}=4)$ in the control before Hist 1 , and $-4.0 \pm 2.2 \times 10^{-7} \mathrm{~cm} \cdot \mathrm{s}^{-1}(\mathrm{n}=4)$ during Hist 1 . These values were not significantly different. After epithelial damage, PDTPA was significantly increased $(\mathrm{p}<0.01)$ to $-400 \pm 130 \times 10^{-7} \mathrm{~cm} \cdot \mathrm{s}^{-1}(\mathrm{n}=4)$ in the control preceding Hist 2. This decreased to $-240 \pm 80 \times 10^{-7} \mathrm{~cm} \cdot \mathrm{s}^{-1}(\mathrm{n}=4)$ during Hist 2, a change that just failed to reach statistical significance $(\mathrm{p}=0.08)$. 
a) Ep+/Hist 1

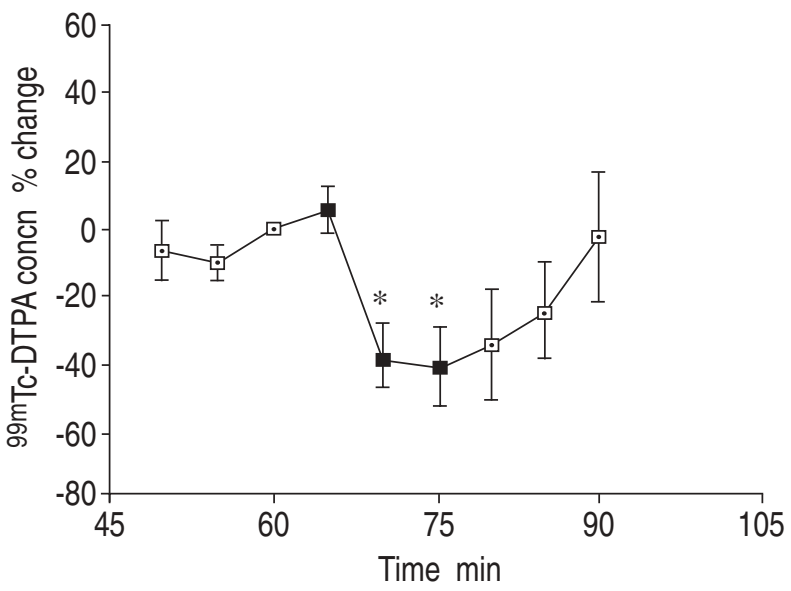

b) Ep-/Hist 2

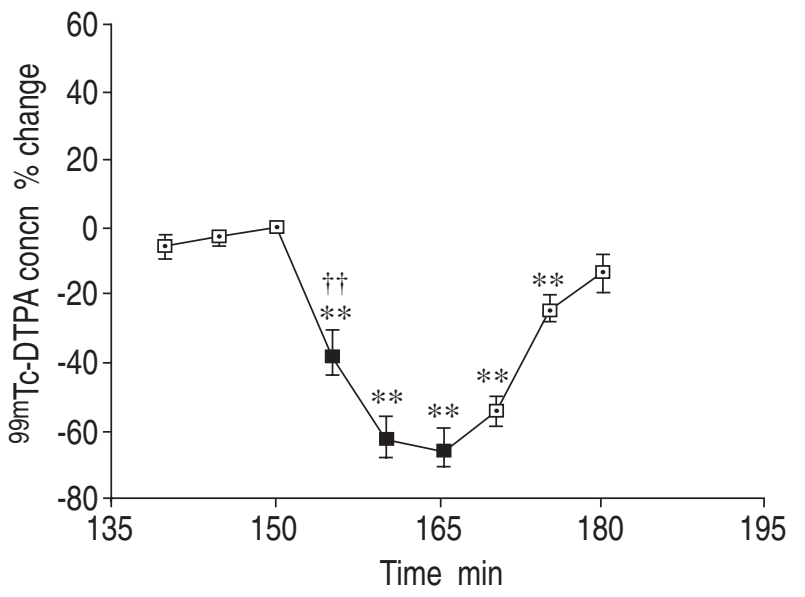

Fig. 7. - Epithelial damage. Venous $99 \mathrm{~m}$ Tc-DTPA concentration in response to two $15 \mathrm{~min}$ administrations of $100 \mu \mathrm{M}$ histamine $(\mathrm{n}=5)$ : a) before (Ep+/Hist 1); and b) after epithelial damage induced by $0.2 \%$ Triton X-100 (Ep-/Hist 2). Each point represents mean concentration over a 5 min period. Results were normalized to the last 5 min of the preceding control. Filled squares represent period of exposure to histamine. Vertical bars show SEM. *: $\mathrm{p}<0.05$; **: $\mathrm{p}<0.01$ (vs 10-15 min period of preceding control, paired t-test); ${ }^{\dagger}: \mathrm{p}<0.01$ (vs Ep+/Hist 1, unpaired t-test). Ep: epithelium; Hist: histamine; concn: concentration; 99mTc-DTPA: 99mtechnetium-diethylenetriamine pentaacetic acid.

Potential difference. Histamine had no effect on the PD across the tracheal wall $(-28.6 \pm 3.5 \mathrm{mV}$ during Hist 1 compared with $-28.8 \pm 3.7 \mathrm{mV}$ in the preceding control in the epithelial damage experiments, $n=5$ ). Exposure of the tracheal lumen to $0.2 \%$ Triton X-100 always reduced the PD to zero. No recovery of the PD occurred.

\section{Discussion}

This is the first study in vivo to demonstrate that airway epithelial damage produces a vascular hyperresponsiveness to a drug given intraluminally. Intraluminal histamine produced more rapid and larger changes in blood flow after epithelial damage than before. Histamine also produced a greater decrease in venous concentration and output of the low molecular weight hydrophilic tracer, $99 \mathrm{~m}$ Tc-DTPA, after epithelial damage. a) Ep+/Hist 1

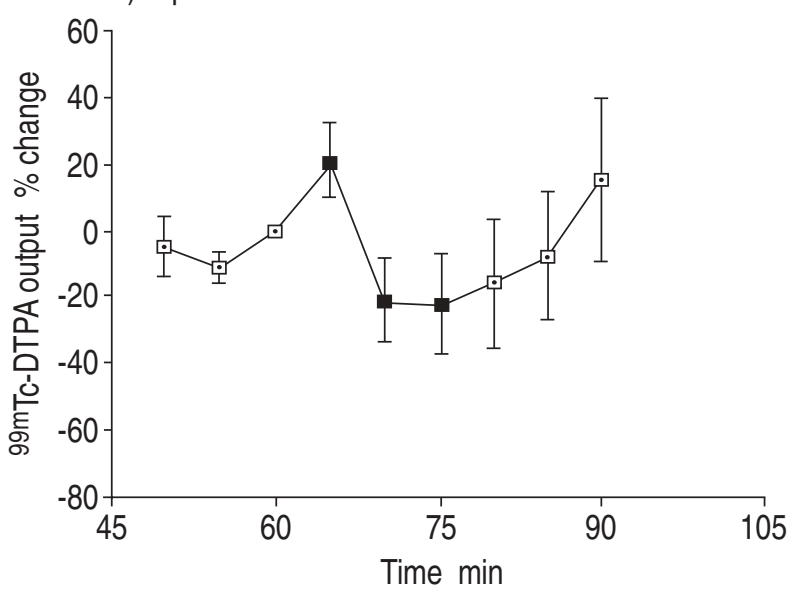

b) Ep-/Hist 2

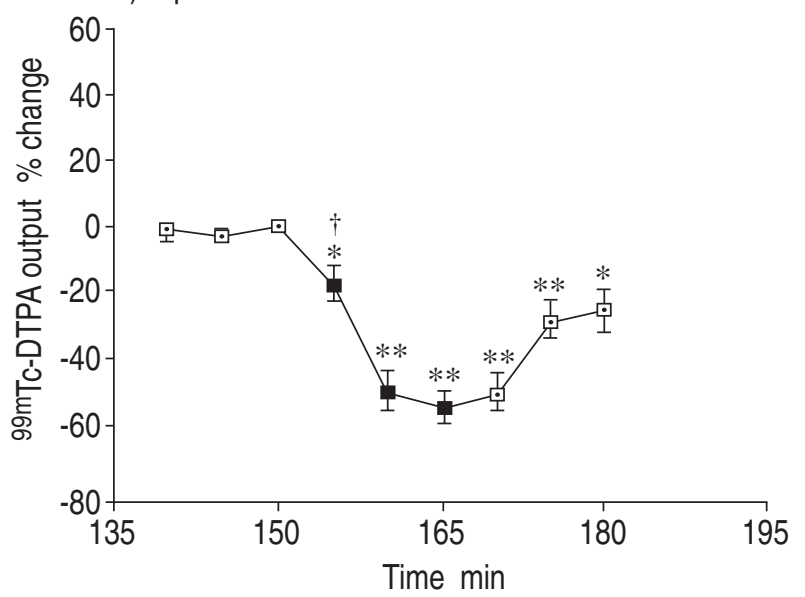

Fig. 8. - Epithelial damage. Venous ${ }^{99 \mathrm{~m} T c-D T P A}$ output in response to two $15 \mathrm{~min}$ administrations of $100 \mu \mathrm{M}$ histamine $(\mathrm{n}=5)$ : a) before (Ep+/Hist 1); and b) after epithelial damage induced by $0.2 \%$ Triton X-100 (Ep-/Hist 2). Each point represents mean output over a $5 \mathrm{~min}$ period. Results were normalised to the first $5 \mathrm{~min}$ of the preceding control. Filled squares represent period of exposure to histamine. Vertical bars show SEM. *: $\mathrm{p}<0.05$; **: $\mathrm{p}<0.01$ (vs 10-15 min period, paired t-test); $\dagger: \mathrm{p}<0.05$ ( $v s$ Ep+/Hist 1, unpaired t-test). For abbreviations see legend to figure 7 .

\section{Epithelial damage and permeability}

The most likely explanation for these results is that epithelial damage increases the penetration of histamine to the vasculature. Triton X-100 increased PDTPA by almost 100 fold. We have previously shown that this treatment causes sloughing of epithelial cells, leaving only a single layer of basal cells in many areas [4]. The extent to which the vascular uptake of histamine mirrors that of 99mTc-DTPA is not known. Histamine is hydrophilic [1] but we have no information on whether it is more or less hydrophilic than $99 \mathrm{mTc}-\mathrm{DTPA}$. It has a lower molecular weight (184 Da) than 99mTc-DTPA (492 Da) and, unlike the latter, it is a charged molecule at physiological pH with a pKa of 9.8 [1]. Epithelial remo$\mathrm{val}$ in the guinea-pig trachea in vitro increased histamine diffusivity from $3 \times 10^{-8}$ to $7 \times 10^{-6} \mathrm{~cm}^{2} \cdot \mathrm{s}^{-1}$ (W. Mitzner, personal communication cited in [11]), whilst antigen challenge in monkeys produced a fivefold increase in the 
levels of radioactively-labelled histamine in the bloodstream following delivery by aerosol to the airways [12]. In contrast, a study using human peripheral airways in vitro did not find an increase in histamine penetration after epithelial damage induced by hydrogen peroxide [11], but this might be due to methodological problems.

\section{Epithelial damage, histamine and blood flow}

Epithelial damage may also alter the relative contribution of the various mechanisms by which histamine increases blood flow. Histamine stimulates the release of nitric oxide and possibly other vasodilators from endothelium $[13,14]$, as well as having a direct action on vascular smooth muscle. In addition, the epithelium itself is a source of vasodilators, including prostaglandins [15], nonprostanoids [16, 17] and nitric oxide [18, 19], as well as vasoconstrictors (such as prostaglandins [20] and endothelin [21, 22]). Histamine releases a nonprostanoid from guinea-pig epithelium which relaxes vascular smooth muscle [17]. Thus, damage to the epithelium may not only increase the penetration of histamine but also modify the degree of histamine-induced vasodilatation which is attributable to epithelium-derived factors.

Histamine can also act on irritant receptors and Cfibres to produce central and local axon reflexes [23-25]. The lack of effect of luminal histamine on systemic arterial pressure either before or after epithelial damage suggests that C-fibre central reflexes were not appreciably activated but epithelial damage might increase activation of local axon reflexes by histamine.

If histamine permeability increased as much as that of 99mTc-DTPA after epithelial damage, then it is perhaps surprising that larger changes in blood flow were not seen. However, by expressing results over a $5 \mathrm{~min}$ period we may have underestimated the maximum flow change induced by histamine. What is very clear is that after epithelial damage histamine produced much more rapid changes in blood flow. Flow also returned to baseline more rapidly after epithelial damage; this could reflect quicker clearance of histamine by the bloodstream as well as the absence of epithelium-derived vasodilators. The cause of the reduction in blood flow at the end of the control after Hist 2 (fig. 4) is not known.

\section{Histamine-induced changes in ${ }^{99 m}$ Tc-DTPA permea- bility}

99mTc-DTPA has been used in this study to show how drug administration to the tracheal lumen affects the permeability of small hydrophilic molecules. Uptake of 99mTc-DTPA into venous blood is affected not only by epithelial integrity [4] but also by blood flow [5]. Luminal histamine caused a decrease in venous $99 \mathrm{~m} \mathrm{Tc}-$ DTPA concentration and output, as well as an increase in blood flow. A negative relationship between blood flow and 99mTc-DTPA uptake has been observed in response to a variety of stimuli in this model, including histamine and other drugs given intravascularly, and luminal hyperosmolarity $[5,10]$. The cause is unknown, but may reflect changes in capillary fluid flux.

Histamine produced a larger reduction in $99 \mathrm{~m}$ Tc-DTPA concentration and output after epithelial damage, particularly during the first $5 \mathrm{~min}$ of exposure (figs. 7 and 8). This is true even when results are expressed as percentage changes from baseline, but of course the absolute change is very much greater because the baseline PDTPA was increased 100 fold by epithelial damage. Although we did not measure 99mTc-DTPA concentration in the control experiments and, therefore, have to be cautious about the interpretation of the effects of histamine on 99mTc-DTPA concentration after epithelial damage, it seems likely that this effect is a direct consequence of the enhanced vascular response. Epithelial damage may also lead to a more rapid or pronounced oedema in response to histamine. In addition, if the effect of histamine on tracheal smooth muscle contraction was enhanced after epithelial damage, as has been observed in vitro [19], then the mucosal depth might be increased as a result of changes in tissue geometry. All these changes might contribute to the reduction in $99 \mathrm{~m}$ Tc-DTPA output.

The decrease in venous $99 \mathrm{~m}$ Tc-DTPA concentration in response to luminal histamine in tracheas with an intact epithelium is probably not due to a reduction in penetration of the tracer across the epithelium itself, since histamine had no effect on PD in tracheas with an intact epithelium. A similar lack of effect of mucosally-applied histamine on PD has been observed in vitro [26-29] (although some studies have shown an effect when histamine is applied to the submucosa $[27,30,31])$. However, the lack of effect on PD contrasts with the finding that luminal histamine increased the penetration of macromolecules across the guinea-pig tracheal wall [32].

The histamine-induced effects on blood flow and $99 \mathrm{~m}$ TcDTPA uptake are clearly altered by epithelial damage. This suggests that vascular hyperresponsiveness may be a feature of asthma, since a relationship between epithelial damage and the severity of asthma has been shown by some studies $[8,9]$ (though not by all [33]). The importance of the vascular hyperresponsiveness is unclear. A study investigating the contribution of vascular volume to airway narrowing in sheep suggested that a 50\% increase in vascular volume caused by inhaled histamine had little effect on airway narrowing, at least in large cartilaginous airways [34].

In conclusion, this study has shown that after epithelial damage histamine produces a greater increase in tracheal blood flow and a greater decrease in venous 99mTc-DTPA concentration. Although we have not established whether epithelial and endothelial factors are involved in this response, it seems likely that these effects are at least partly due to an increase in histamine permeability, since the permeability coefficient of another hydrophilic molecule, ${ }^{99 m}$ Tc-DTPA, was greatly increased. Our results suggest that inhaled hydrophilic drugs, through their action on the vasculature, will modulate their own uptake and that there may be a difference in the speed of onset, duration of action and magnitude of effect of such drugs between airways with an intact epithelium and those with substantial epithelial damage. 


\begin{abstract}
Acknowledgements: The authors thank S. Duneclift for the preparation of graphs. UMW was funded by the National Asthma Campaign and $\mathrm{ZH}$ by the Wellcome Trust.
\end{abstract}

\section{References}

1. Grundstrom N, Lindstrom EG, Axelsson KL, Andersson RG. Epithelial modulation of allergen and drug effects in guinea-pig airways. J Appl Physiol 1992; 72: 1953-1959.

2. Wangensteen OD, Schneider LA, Fahrenkrug SC, Brottman GM, Maynard RC. Tracheal epithelial permeability to nonelectrolytes: species differences. J Appl Physiol 1993; 75: 1009-1018.

3. Woods AJ, Widdicombe JG. Removal of tracheal epithelia alters the effects of airway osmolality on tracer flux across the ferret trachea in vitro. J Physiol 1994; 475: 1291P.

4. Wells UM, Woods AJ, Hanafi Z, Widdicombe JG. Epithelial damage alters the effect of tracheal osmolality on water and tracer fluxes in sheep in vivo. J Appl Physiol 1995; 78: 1921-1930.

5. Hanafi Z, Corfield DR, Webber SE, Widdicombe JG. Tracheal blood flow and luminal clearance of $99 \mathrm{~m}$ TcDTPA in sheep. J Appl Physiol 1992; 73: 1273-1281.

6. Cockcroft DW, Killian DN, Mellon JJ, Hargreave FE. Bronchial reactivity to inhaled histamine: a method and clinical survey. Clin Allergy 1977; 7: 235-243.

7. Ryan G, Latimer KM, Dolovich J, Hargreave FE. Bronchial responsiveness to histamine: relationship to diurnal variation of peak flow rate, improvement after bronchodilatation, and airway calibre. Thorax 1982; 37: 423429.

8. Laitinen LA, Heino M, Laitinen A, Kava T, Haahtela T. Damage of the airway epithelium and bronchial reactivity in patients with asthma. Am Rev Respir Dis 1985; 131: 599-606.

9. Jeffery PK, Wardlaw A, Nelson FC, Collins JV, Kay AB. Bronchial biopsies in asthma: an ultrastructural quantification study and correlation with hyperreactivity. Am Rev Respir Dis 1989; 140: 1745-1753.

10. Wells UM, Hanafi Z, Widdicombe JG. Osmolality alters tracheal blood flow, tracer uptake and ion and water fluxes in sheep in vivo. J Appl Physiol 1994; 77: 24002407.

11. Hulsmann AR, Raatgeep, HR, den Hollander JC, et al. Oxidative epithelial damage produces hyperresponsiveness of human peripheral airways. Am J Respir Crit Care Med 1994; 149: 519-525.

12. Boucher RC, Paré PD, Hogg JC. Relationship between airway hyperreactivity and hyperpermeability in Ascarissensitive monkeys. J Allergy Clin Immunol 1979; 64: 197-201.

13. Van de Voorde J, Leusen I. Role of the endothelium in the vasodilator response of rat thoracic aorta to histamine. Eur J Pharmacol 1983; 87: 113-120.

14. Ortiz JL, Labat C, Norel X, Gorenne I, Verley J, Brink $\mathrm{K}$. Histamine receptors on human isolated pulmonary arterial muscle preparations: effect of endothelial cell removal and nitric oxide inhibitors. J Pharm Exp Therap 1992; 260: 762-767.

15. Stuart-Smith K, Vanhoutte PM. Arachidonic acid evokes epithelium-dependent relaxations in canine airways. $J$ Appl Physiol 1988; 65: 2170-2178.

16. Ilhan M, Sahin I. Tracheal epithelium releases a vascular smooth muscle relaxant factor: demonstration by bioassay. Eur J Pharmacol 1986; 131: 293-296.
17. Hay DPW, Muccitelli RM, Page CP, Spina D. Correlation between airway epithelium-induced relaxation of rat aorta in the co-axial bioassay and cyclic nucleotide levels. $\mathrm{Br}$ J Pharmacol 1992; 105: 954-958.

18. Burke-Wolin T, Matsui K, Wolin MS, Gurtner GH. Epithelium-dependent nitric oxide production by bovine airways. Am Rev Respir Dis 1992; 145: A400.

19. Nijkamp FP, van der Linde HJ, Folkerts G. Nitric oxide synthesis inhibitors induce airway hyperresponsiveness in the guinea-pig in vivo and in vitro: role of the epithelium. Am Rev Respir Dis 1993; 148: 727-734.

20. Wilkens JH, Becker A, Wilkens H, et al. Bioassay of a tracheal smooth muscle-constricting factor released by respiratory epithelial cells. Am J Physiol 1992; 263: L137-L141.

21. Rozengurt N, Springall DR, Polak JM. Localization of endothelin-like immunoreactivity in airway epithelium of rats and mice. J Pathol 1990; 16: 5-8.

22. Marciniak SJ, Plumpton C, Barker PJ, Huskissen NS, Davenport AP. Localisation of immunoreactive endothelin and proendothelin in the human lung. Pulm Pharmacol 1992; 5: 175-182.

23. Coleridge HM, Coleridge JCG, Baker DG, Ginzel KH, Morrison MA. Comparison of the effects of histamine and prostaglandins on afferent $\mathrm{C}$-fibre endings and irritant receptors in the intrapulmonary airways. Adv Med Biol 1978; 99: 291-305.

24. Barnes PJ. Asthma as an axon reflex. Lancet 1986; i: 242-244.

25. Coleridge HM, Coleridge JCG. Reflexes evoked from the tracheobronchial tree and lungs. In: Cherniack NS, Widdicombe JG, eds. Handbook of Physiology. 3. The Respiratory System. Vol. II. Control of Breathing. Bethesda, American Physiological Society, 1986; 395429.

26. Durand J, Durand-Arczynska W, Haab P. Volume flow, hydraulic conductivity, and electrical properties across bovine tracheal epithelium in vitro: effect of histamine. Pflügers Arch 1981; 392: 40-45.

27. Sugahara K, Kiyota T, Baba T, Nakamura M, Morioka T. Effects of autonomic agents on ion transport by canine tracheal epithelium. Jap J Physiol 1989; 39: 412428.

28. Hanafi Z, Webber SE, Widdicombe JG. Permeability of ferret trachea in vitro to ${ }^{99 \mathrm{~m} T c-D T P A}$ and ${ }^{14} \mathrm{C}$ - antipyrine. J Appl Physiol 1994; 77: 1263-1273.

29. Devalia JL, Godfrey RWA, Sapsford RJ, Severs NJ, Jeffery PK, Davies RJ. No effect of histamine on human bronchial epithelial cell permeability and tight junctional integrity in vitro. Eur Respir J 1994; 7: 1958-1965.

30. Corrales RJ, Coleman DL, Jacoby DB, et al. Ion transport across cat and ferret tracheal epithelia. J Appl Physiol 1986; 61: 1065-1070.

31. Marin MG, Davis B, Nadel JA. Effect of histamine on electrical and ion transport properties of tracheal epithelium. J Appl Physiol 1977; 42: 735-738.

32. Boucher RC, Ranga V, Paré PD, Inoue S, Moroz LA, Hogg JC. The effect of histamine and methacholine on guinea-pig tracheal permeability to HRP. J Appl Physiol: Respirat Environ Exercise Physiol 1978; 45: 939-948.

33. Lozewicz S, Wells C, Gomez E, Ferguson H, Richman P, Devalia J, Davies RJ. Morphological integrity of the bronchial epithelium in mild asthma. Thorax 1990; 45: 12-15.

34. Baile EM, Sotres-Vega A, Paré PD. Airway blood flow and bronchovascular congestion in sheep. Eur Respir $J$ 1994; 7: 1300-1307 